\title{
Use of Entomopathogenic Nematodes and Thyme Oil to Suppress Plant-Parasitic Nematodes on English Boxwood
}

\author{
Enrique E. Pérez, Research Scientist, Monsanto Company, 700 Chesterfield Parkway West, Chesterfield, MO \\ 63017; and Edwin E. Lewis, Associate Professor, Departments of Nematology and Entomology, University of Cali- \\ fornia, Davis, CA 95616
}

\begin{abstract}
Pérez, E. E., and Lewis, E. E. 2006. Use of entomopathogenic nematodes and thyme oil to suppress plant-parasitic nematodes on English boxwood. Plant Dis. 90:471-475.

A 2-year experiment was conducted to test suppression of plant-parasitic nematodes on English boxwood using entomopathogenic nematodes and 3.5\% thyme oil formulated as Promax. Treatments were Steinernema riobrave formulated as BioVector and $S$. feltiae formulated as Nemasys, both applied at a rate of 2.5 billion infective juveniles/ha, thyme oil at rate of 9.3 liters/ha, and nontreated control. In the 2001 season, treatment with $S$. feltiae reduced $(P \leq 0.05)$ the population growth of Tylenchorhynchus sp. 7 days after treatment and Hoplolaimus sp. 30 and 60 days after treatment. Treatment with $S$. riobrave reduced $(P \leq 0.05)$ the population growth of all plant-parasitic nematode species at all sampling dates, with the exception of Mesocriconema sp. 30 days after treatment and Tylenchorhynchus sp. and Rotylenchus buxophilus 60 days after treatment. Treatment with thyme oil reduced $(P \leq 0.05)$ the population growth of all plant-parasitic nematode genera at all sampling dates except Tylenchorhynchus sp. and $R$. buxophilus 60 days after treatment. In the 2002 season, treatment with $S$. feltiae had no effect on nematode population growth. Treatment with $S$. riobrave reduced $(P \leq 0.05)$ the population growth of $R$. buxophilus 7 days after treatment, and all plant-parasitic nematodes 30 and 60 days after treatment except Hoplolaimus sp. 30 days after treatment and Mesocriconema sp. 60 days after treatment. Treatment with thyme oil reduced $(P \leq 0.05)$ the population growth at all sampling dates of plant-parasitic nematodes except Mesocriconema sp. 60 days after treatment.
\end{abstract}

English boxwood, Buxus sempervirens L. var. suffruticosa, is one of the most common woody ornamental plants found in landscapes in Virginia. Boxwood decline is a serious problem in field-grown nursery stock and landscape plantings (12). The etiology of boxwood decline has been attributed to unfavorable environmental conditions combined with plant-parasitic nematodes and certain root rot fungi $(2,3,12)$. The pathogenicity of the spiral nematode, Rotylenchus buxophilus Golden, to English boxwood has been demonstrated (17). The spiral nematode is a migratory ectoparasite that attacks mostly small feeder roots. During feeding, the nematodes become partially embedded and occasionally penetrate the root tips. Symptoms of nematode-induced decline in the greenhouse and field include bronzing of foliage, stunting, and root necrosis (3).

Nematode feeding on boxwood roots diminishes the capacity of roots to absorb water and nutrients and provides portals of entry for other plant pathogens such as

Corresponding author: Enrique E. Perez

E-mail: enrique.e.perez@monsanto.com

Accepted for publication 25 July 2005.

DOI: 10.1094/PD-90-0471

(C) 2006 The American Phytopathological Society fungi and bacteria. As a result, plants infested with nematodes become yellow and less productive. Boxwood plants may require three or four growing seasons to develop decline symptoms caused by nematodes (1). By the time early foliage symptoms are expressed, $50 \%$ or more of the root system has been destroyed, exhibiting typical symptoms of root rot (13). Because boxwoods have to be replaced when severe symptoms develop, early disease diagnosis and subsequent management are important.

Most chemical nematicides for use on ornamentals are classified as restricted use pesticides and are only available to personnel with valid pesticide licenses. Nurseries may utilize chemical nematicide treatments to produce nematode-free boxwoods in field plantings. Nematodes that escape treatment, however, can resurge quickly, requiring several nematicide applications to produce nematode-free stock. Nematode-free stock can still be affected by boxwood decline if planted in soil infested with nematodes.

Due to safety and environmental concerns, there are few registered chemical nematicides, and their use is highly restricted. Developing alternatives to chemical nematicides is essential to manage nematode-associated diseases on ornamentals. Recent attempts to develop alternative methods to manage plant-parasitic nema- todes include the use of entomopathogenic nematodes and various biologically derived nematicides. Some species of entomopathogenic nematodes suppressed plant-parasitic nematodes in field and greenhouse experiments $(4-6,8,10,15,16)$. The level of plant-parasitic nematode suppression in turfgrass using entomopathogenic nematodes was similar to or better than that of a chemical nematicide (6). Nematicidal activity of essential oils from plants has been tested in greenhouse and laboratory experiments with varying degrees of success. Oka et al. (14) tested the essential oils associated with 27 species of herbs and found that several of the oils had nematicidal activity, including the essential oil extracted from common thyme (Thymus vulgaris L.). Our objective was to test suppression of plant-parasitic nematodes on boxwood using the entomopathogenic nematodes Steinernema feltiae and S. riobrave and a new broad-spectrum nematicide with thyme oil as the active ingredient.

\section{MATERIALS AND METHODS}

Experiments were conducted in 2001 and 2002 at the Virginia Tech Kentland Experimental Research Farm, McCoy, VA. The experimental site had an English boxwood plantation for approximately 45 to 55 years. Several boxwood plants were showing the typical symptoms of boxwood decline. The soil type was a Wheeling silt loam (20\% sand, $64 \%$ silt, $16 \%$ clay, $1.5 \%$ organic matter).

The entomopathogenic nematodes used were infective juveniles (IJ) of $S$. riobrave formulated as BioVector by Certis (Columbia, MD) and IJ of $S$. feltiae formulated as Nemasys by Becker Underwood (Ames, IA). Treatments were $S$. riobrave, S. feltiae, $3.5 \%$ thyme oil formulated as Promax by Bio Huma Netics Inc. (Chandler, AZ), and nontreated control. The experimental design was a completely randomized block. Each experimental unit consisted of two boxwood plants planted between 2.5 and $3.5 \mathrm{~m}$ apart. One experimental unit was separated from the next by at least one nontreated boxwood plant. There were four experimental units per block and a total of six blocks. Each experimental unit in a block received one of the following treatments: (i) $S$. riobrave applied at a rate of 2.5 billion $I J / h a$, (ii) $S$. feltiae applied at the same rate as $S$. rio- 
brave, (iii) thyme oil at rate of 9.3 liters/ha, and (iv) water (nontreated control). Before treatment application, a $3-\mathrm{m}^{2}$ area around each plant was weeded by hand and drenched with approximately 15 liters of water. Treatments were applied on 18 June 2001 and 28 June 2002.

In 2001, soil samples for nematode assay were collected on 11 June (pretreatment sample), 25 June, 18 July, and 17 August. In 2002, soil samples were collected on 21 June (pretreatment sample), 5 July, 29 July, and 28 August. Nematode soil samples consisted of 15 to 20 cores $(2.5 \mathrm{~cm}$ diameter $\times 20 \mathrm{~cm}$ deep) taken in the treated area around the boxwood plants. The 15 to 20 cores were mixed manually, and a $100-\mathrm{cm}^{3}$ subsample was collected. The subsamples were wet-sieved through nested $850-\mu \mathrm{m}$ and $25-\mu \mathrm{m}$ pore sieves. The material retained on the $25-\mu \mathrm{m}$ pore sieve was processed by centrifugal flotation (11). The extracted nematodes were dispersed in water in a gridded counting dish and counted. Samples were evaluated for plant-parasitic and free-living (non-stylet-bearing) nematodes. Plantparasitic nematode species were identified at least to genus.

Nematode population densities after treatment application were expressed as a percentage of pretreatment population densities. The natural logarithm of mean nematode percentage of pretreatment population densities were subjected to the analysis of variance for a completely randomized block design using SAS (SAS Institute, Cary, NC). Means among treatments within each nematode group at each sampling date were compared using Fisher's protected LSD.

\section{RESULTS}

Population densities of plant-parasitic and free-living nematodes were recorded before treatment application (Table 1). Population densities of the plant-parasitic nematodes $R$. buxophilus, Mesocriconema sp., Tylenchorhynchus sp., Hoplolaimus sp., and free-living (non-stylet-bearing) nematodes were counted to evaluate treat- ment effects. Other plant-parasitic nematode genera were present but not included in the analysis because their frequency and population densities were low.

2001 season. In plots treated with $S$. riobrave, population growth of all plantparasitic nematode species was less $(P \leq$ $0.05)$ than in the control plots 7 days after treatment (Fig. 1A to D). Treatment with $S$. riobrave had no effect $(P>0.05)$ on the free-living nematode population growth 7 days after treatment (Fig. 1E). In plots treated with $S$. riobrave, 30 days after treatment, population growth of all plantparasitic nematode species and free-living nematodes was less $(P \leq 0.05)$ than in the control plots, except Mesocriconema sp. (Fig. 1A to E). In plots treated with $S$. riobrave, 60 days after treatment the population growth of Hoplolaimus sp. and Mesocriconema sp. was less $(P \leq 0.05)$ than in the control plots (Fig. 1B and C). Treatment with $S$. riobrave had no effect $(P>0.05)$ on the free-living nematode population growth 60 days after treatment (Fig. 1E). Treatment with $S$. feltiae reduced $(P \leq 0.05)$ the population growth of Tylenchorhynchus sp. 7 days after treatment (Fig. 1A) and the population growth of Hoplolaimus sp. 30 and 60 days after treatment (Fig. 1B). Treatment with $S$. feltiae had no effect $(P>0.05)$ on the freeliving nematode population growth at any sampling date (Fig. 1E). In plots treated with thyme oil, 7 and 30 days after treatment, population growth of plant-parasitic nematode species was less $(P \leq 0.05)$ than in the control plots (Fig. 1A to D). Population growth of free-living nematodes was less $(P \leq 0.05)$ than in the control plots 30 days after treatment (Fig. 1E). In plots treated with thyme oil, 60 days after treatment, the population growth of Hoplolaimus sp. and Mesocriconema sp. was less $(P \leq 0.05)$ than in the control plots (Fig. 1B and C). Treatment with thyme oil had no effect $(P>0.05)$ on the free-living nematode population growth 60 days after treatment (Fig. 1E).

2002 season. In plots treated with $S$. riobrave, 7 days after treatment, popula- tion growth of $R$. buxophilus was less ( $P \leq$ 0.05 ) than in the control plots (Fig. 2D). In plots treated with $S$. riobrave, 30 days after treatment, population growth of all plantparasitic nematode species was less $(P \leq$ $0.05)$ than in the control plots, except Hoplolaimus sp. (Fig. 2A to D). In plots treated with $S$. riobrave, 60 days after treatment, population growth of all plant-parasitic nematode species was less $(P \leq 0.05)$ than in the control plots, except Mesocriconema sp. (Fig. 2A to D). Treatment with $S$. riobrave had no effect $(P>0.05)$ on the freeliving nematode population growth at any sampling date (Fig. 2E). Treatment with $S$. feltiae had no effect $(P>0.05)$ on the population growth of either plant-parasitic or free-living nematodes at any sampling date (Fig 2A to E). In plots treated with thyme oil, 7 and 30 days after treatment, population growth of all plant-parasitic nematode species and free-living nematodes was less $(P \leq 0.05)$ than in the control plots (Fig. 2A to E). In plots treated with thyme oil, 60 days after treatment, population growth of all plant-parasitic nematode species was less $(P \leq 0.05)$ than in the control plots, except Mesocriconema sp. (Fig. 2A to D). Treatment with thyme oil had no effect $(P>0.05)$ on the freeliving nematode population growth 60 days after treatment (Fig. 2E).

\section{DISCUSSION}

Application of 2.5 billion IJ/ha of $S$. riobrave suppressed the population growth of $R$. buxophilus 7 and 30 days after treatment in both seasons. The duration of suppression using $S$. riobrave on the other plant-parasitic nematode genera varied between seasons. For example in 2001, $S$. riobrave suppressed the population growth of Tylenchorhynchus sp. and Hoplolaimus sp. at 7 and 30 days after treatment, whereas they were suppressed only at 30 days after treatment in the 2002 season. The population growth of Tylenchorhynchus sp. and Hoplolaimus sp. in 2002 was less than that in the control plots, but the differences were not statistically significant. Biological or environmental factors

Table 1. Mean ${ }^{\mathrm{a}}$ population densities of Tylenchorhynchus sp., Hoplolaimus sp., Mesocriconema sp., Rotylenchus buxophilus, and free-living ${ }^{\mathrm{b}}$ nematodes in soil samples taken from the vicinity of boxwood roots before treatment application. 2001 and 2002 seasons

\begin{tabular}{|c|c|c|c|c|c|}
\hline \multirow[b]{2}{*}{ Treatment $^{\mathrm{c}}$} & \multicolumn{5}{|c|}{ Nematodes per $100 \mathrm{~cm}^{3}$ of soil } \\
\hline & Tylenchorhynchus sp. & Hoplolaimus sp. & Mesocriconema sp. & R. buxophilus & Free-living \\
\hline \multicolumn{6}{|l|}{2001 season } \\
\hline Control & $359 \pm 56$ & $186 \pm 37$ & $133 \pm 47$ & $163 \pm 49$ & $256 \pm 54$ \\
\hline Steinernema feltiae & $431 \pm 75$ & $495 \pm 65$ & $112 \pm 35$ & $147 \pm 32$ & $222 \pm 30$ \\
\hline S. riobrave & $669 \pm 58$ & $233 \pm 78$ & $131 \pm 50$ & $364 \pm 46$ & $297 \pm 65$ \\
\hline Thyme oil & $289 \pm 76$ & $145 \pm 75$ & $156 \pm 54$ & $175 \pm 58$ & $338 \pm 72$ \\
\hline \multicolumn{6}{|l|}{2002 season } \\
\hline Control & $327 \pm 40$ & $178 \pm 53$ & $138 \pm 37$ & $305 \pm 89$ & $224 \pm 51$ \\
\hline S. feltiae & $283 \pm 45$ & $76 \pm 35$ & $81 \pm 32$ & $88 \pm 18$ & $148 \pm 74$ \\
\hline S. riobrave & $182 \pm 77$ & $259 \pm 65$ & $73 \pm 31$ & $116 \pm 31$ & $186 \pm 41$ \\
\hline Thyme oil & $486 \pm 45$ & $213 \pm 78$ & $98 \pm 30$ & $122 \pm 35$ & $216 \pm 57$ \\
\hline
\end{tabular}

${ }^{a} \pm$ standard error of the mean

b Non-stylet-bearing nematodes.

c Samples were taken on 11 June 2001 and on 21 June 2002. Treatments were applied on 18 June 2001 and on 28 June 2002. 


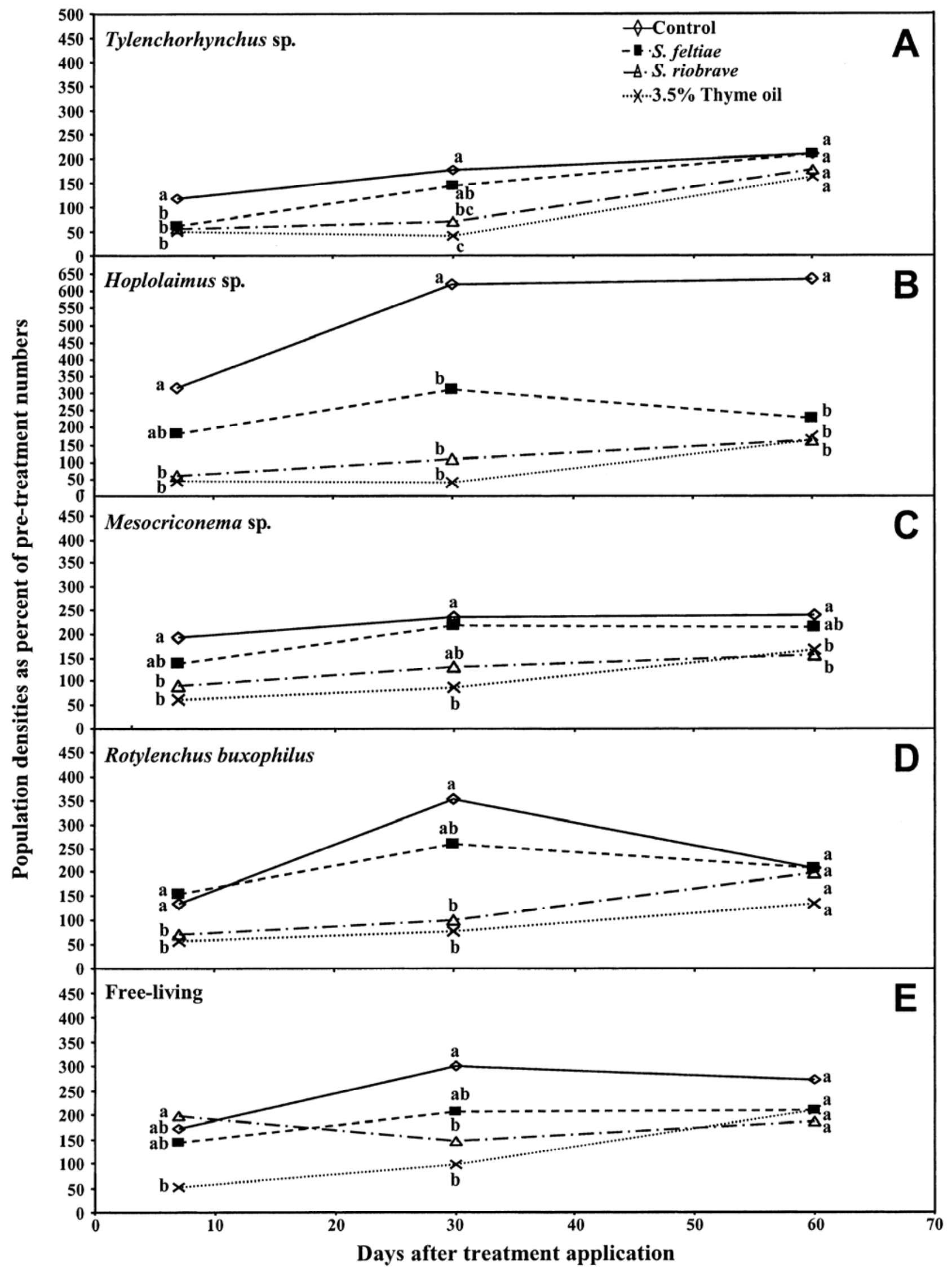

Fig. 1. 2001 season. Nematode population densities as percentage of pretreatment numbers from soil samples taken around boxwood plants at different times after treatment with Steinernema feltiae, S. riobrave, thyme oil, or nontreated control. A, Tylenchorhynchus sp., B, Hoplolaimus sp., C, Mesocriconema sp., D, Rotylenchus buxophilus, E, free-living (non-stylet-bearing) nematodes. Within a nematode group and sampling time, points followed by the same letter are not significantly different $(P>0.5)$ according to Fisher's protected LSD $(n=6)$. 


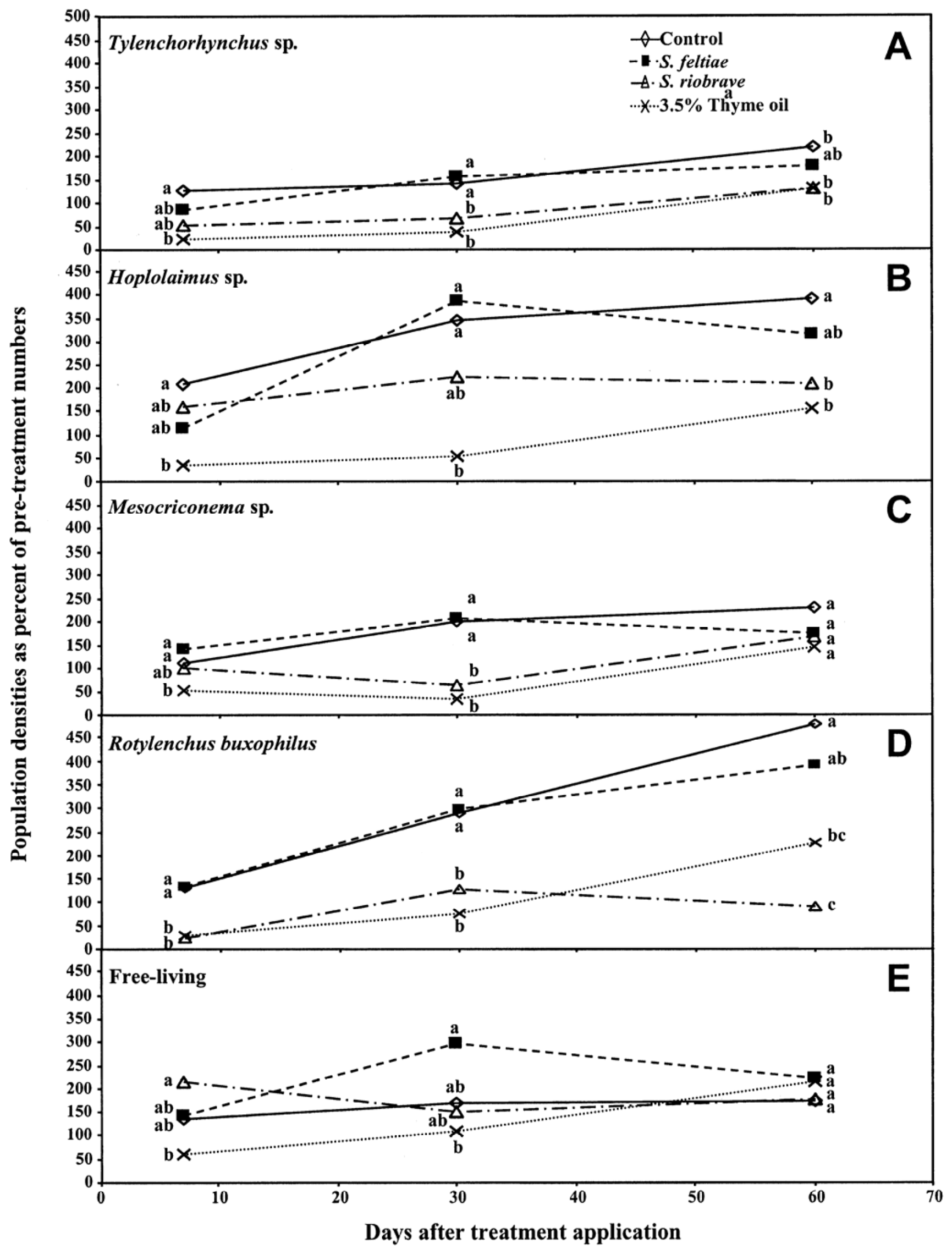

Fig. 2. 2002 season. Nematode population densities as percentage of pretreatment numbers from soil samples taken around boxwood plants at different times after treatment with Steinernema feltiae, S. riobrave, thyme oil, or nontreated control. A, Tylenchorhynchus sp., B, Hoplolaimus sp., C, Mesocriconema sp., D, Rotylenchus buxophilus, E, free-living (non-stylet-bearing) nematodes. Within a nematode group and sampling time, points followed by the same letter are not significantly different $(P>0.5)$ according to Fisher's protected LSD $(n=6)$. 
may have caused the difference in suppression between the two seasons. The suppressive effect of $S$. riobrave on plantparasitic nematodes in this study agrees with a previous study showing that the same application rate of $S$. riobrave suppressed Meloidogyne incognita on tomato (Lycopersicon esculentum Mill.) and $M$. hapla on peanut (Arachis hypogaea L.) in greenhouse experiments $(15,16)$.

Treatments with $S$. feltiae were less effective than treatments with $S$. riobrave. Applications of S. feltiae were suppressive only to Tylenchorhynchus sp. 7 days after treatment and Hoplolaimus sp. 30 and 60 days after treatment in the 2001 season. Previous research has shown that $S$. feltiae applied at the same rate suppressed $M$. incognita on tomato and M. hapla on peanut in greenhouse experiments $(15,16)$. The suppressive effect of $S$. feltiae on plant-parasitic nematodes may vary with plant-parasitic nematode species or life history. It is also possible that experimental differences between greenhouse and field conditions significantly affected the suppressive action of $S$. feltiae on plantparasitic nematodes.

There was one instance in the 2001 season where the treatment of $S$. riobrave suppressed population growth of freeliving nematodes 30 days after application. Ishibashi and Kondo $(8,9)$ reported an increase of the native population of rhabditid free-living nematodes with application of steinernematid nematodes. However Jagdale et al. (10) reported that applications of $S$. carpocapsae had no effect on the population density levels of non-styletbearing nematodes. The implication that entomopathogenic nematodes could affect population densities of free-living nematodes should be investigated further.

Our findings using live $S$. riobrave were similar to those reported by Jagdale et al. (10) using dead or live $S$. carpocapsae to suppress plant-parasitic nematodes on boxwood. Grewal et al. (5) suggested that allelochemicals from the entomopathogenic nematode associated bacteria are antagonistic to plant-parasitic nematodes. The symbiotic bacteria associated with steinernematids, Xenorhabdus spp., pro- duce metabolites that are toxic to nematodes (7). Cell-free extracts of Xenorhab$d u s$ spp. were toxic and repellent to $M$. incognita juveniles and inhibited $M$. incognita egg hatch (5).

Application of thyme oil reduced the population growth of plant-parasitic nematodes for 30 days in both seasons. Population growth of some nematode species remained low compared with the control after 60 days. Population growth reductions after 60 days were observed for Hoplolaimus sp. and Mesocriconema sp. in the 2001 season, and for Tylenchorhynchus sp., Hoplolaimus sp., and $R$. buxophilus in the 2002 season. This nematicide also affected the population growth of freeliving nematodes. In laboratory experiments, thyme essential oils in concentrations of $1,000 \mu \mathrm{l} /$ liter inhibited egg hatch and immobilized second-stage Meloidogyne javanica (14). Ours is the first report of field trials with this material.

Our results suggest that $S$. riobrave and thyme oil have the potential for nematode control on boxwoods and maybe other woody ornamentals. Most plant-parasitic nematode genera were suppressed 30 days after treatment in both seasons, and some genera were suppressed for 60 days after application. Repeated applications may be required to achieve suppression for periods longer than 30 days. Further experiments that evaluate the economic aspects of using entomopathogenic nematodes and thyme oil for nematode control on boxwood should be conducted. Research to test the nematicidal effect of these two products on other parasitic nematode/plant-host systems and soil types is also warranted.

\section{LITERATURE CITED}

1. Benson, D. M. 1978. A direct versus a photographic technique as nondestructive estimates of growth response on perennial ornamentals affected with nematode decline. Plant Dis. Rep. 62:68-70.

2. Benson, D. M., and Barker, K. R. 1978. Aldicarb and 1,2-dibromo-3-chloropropane as postplant treatments for control of nematodes on American boxwood, and Japanese and Chinese hollies. Plant Dis. Rep. 62:209-212.

3. Benson, D. M., Barker, K. R., and Aycock, R. 1976. Effects of density of Helicotylenchus dihystera and Pratylenchus vulnus on American boxwood growing in microplots. J. Nematol 4:322-326.

4. Bird, A. F., and Bird, J. 1985. Observations on the use of insect parasitic nematodes as means of biological control of root-knot nematodes. Int. J. Parasitol. 16:511-516.

5. Grewal, P. S., Lewis, E. E., and Venkatachari, S. 1999. Allelopathy: A possible mechanism of suppression of plant-parasitic nematodes by entomopathogenic nematodes. Nematology 1:735-743.

6. Grewal, P. S., Martin, W. R., Miller, R. W., and Lewis, E. E. 1997. Suppression of plantparasitic nematode populations in turfgrass by application of entomopathogenic nematodes. Biocontrol Sci. Technol. 7:393-399.

7. Hu, K., Jianxiong, L., and Webster, J. M. 1999. Nematicidal metabolites produced by Photorhabdus luminescens (Enterobacteriaceae), bacterial symbiont of entomopathogenic nematodes. Nematology 1:457-469.

8. Ishibashi, N., and Kondo, E. 1986. Steinernema feltiae (DD-136) and S. glaseri: Persistence in soil and bark compost and their influence on native nematodes. J. Nematol. 18:310316.

9. Ishibashi, N., and Kondo, E. 1986. Dynamics of the entomogenous nematode Steinernema feltiae applied to soil with and without nematicide treatment. J. Nematol. 19:404-412.

10. Jagdale, G. B., Somasekhar, N., Grewal, P. S., and Klein, M. G. 2002. Suppression of plant-parasitic nematodes by application of live and dead infective juveniles of an entomopathogenic nematode, Steinernema carpocapsae, on boxwood (Buxus spp.). Biol. Control 24:42-49.

11. Jenkins, W. R. 1964. A rapid centrifugalflotation technique for separating nematodes from soil. Plant Dis. Rep. 48:692.

12. Lambe, R. C., and Wills, W. H. 1975. Decline of English boxwood in Virginia. Plant Dis. Rep. 59:105-108.

13. Montgomery, G. B., Wills, W. H., and Lambe, R. C. 1977. Etiology of decline of English boxwood. Plant Dis. Rep. 61:404-408.

14. Oka, Y., Nacar, S., Putievsky, E., Ravid, U., Yaniv, Z., and Spiegel, Y. 2000. Nematicidal activity of essential oils and their components against the root-knot nematode. Phytopathology 90:710-715.

15. Perez, E. E., and Lewis, E. E. 2002. Use of entomopathogenic nematodes to suppress Meloidogyne incognita on greenhouse tomatoes. J. Nematol. 34:171-174.

16. Perez, E. E., and Lewis, E. E. 2004. Suppression of Meloidogyne incognita and Meloidogyne hapla with entomopathogenic nematodes on greenhouse peanuts and tomatoes. Biol. Control 30:336-341.

17. Siddiqi, M. R. 1974. Rotylenchus buxophilus. C.I.H. Description of Plant-parasitic Nematodes 4(55). 